\title{
Ethics, Invention and Design: Creating Cross-Disciplinary Collaborations
}

\author{
Michael E. Gorman \\ Technology, Culture \& Communications \\ and \\ Systems Engineering \\ University of Virginia
}

When people ask me what I teach, a one sentence answer won't suffice. A psychologist should be teaching psychology courses. Instead, I have to explain that I cover topics like invention and design, engineering ethics and communications. Furthermore, I do research on scientific and technological thinking, which is not one of the recognized specialties in psychology--though a colleague and I are trying to change that (Feist \& Gorman, In Press).

This paper is really the story of how I came to this unusual position--and why I like it. As an undergraduate psychology major, I spent more time on an independent study of scientific thought than on my honors thesis in psychology. In graduate school, I combined social, cognitive, and history of psychology, and also took courses on advanced non-fiction writing. The really interesting questions always seemed to slip between disciplines.

My first job was at Michigan Technological University, an engineering school which wanted a psychologist who could teach writing. One of my many responsibilities was team-teaching a course with W. Bernard Carlson, a historian of technology. He and I wrote a grant proposal to collaborate on a study of the invention of the telephone.

The key to transcending disciplinary boundaries is collaboration (Okada \& Simon, 1997). I provided psychological analyses of scientific problem-solving: Bernie added a deep knowledge of how to do archival research in history of technology, and where the sources were. The grant was funded after Bern moved to the University of Virginia, and I followed him.

A Michigan Tech, I was split between three departments--humanities, social sciences and education. This sounds like an ideal, transdisciplinary situation, but in fact, the politics of funding led the three departments to pull in different directions. In particular, they and I struggled over where psychology should have its home.

At the University of Virginia, I came into what was then the Humanities Division (see paper by Ingrid Soudek). Whereas my departments at Michigan Tech were outside of Engineering and were expected to develop their own majors and graduate programs, the Division was within the Engineering School and was expected to focus on engineering education. The structure of the Division encouraged cooperation across disciplines (see paper by Ingrid Soudek).

My work with Bernie resulted in several scholarly publications (Carlson \& Gorman, 1990; Gorman, 1990; Gorman, Mehalik, Carlson, \& Oblon, 1993). When we showed one or two to a sympathetic Dean, he challenged us to show how some of this work would benefit engineering students. Fair enough. I created a rough design for an extended invention module based on the telephone and ran it by quite a few people, who helped me re-shape it. 
Problem was, I had no course to try it in. So I invented one, and recruited several colleagues to help me teach it, most notably Larry Richards, a psychologist in Mechanical Engineering, and Bill Scherer. a Systems Engineer. The carrot was a grant proposal--I would take the lead in writing it, but would make sure to buy some of their time, and also support a graduate student TA we could share. The Leadership Opportunities Program of the NSF, FIPSE and NEH cut our budget in half, but funded our proposal.

My colleagues may have needed a little carrot to get going, but they threw themselves into the course and have continued to help me teach it every spring for the last five years (Gorman, Richards, Scherer, \& Kagiwada, 1995). We take overlapping responsibilities for different parts of the course, but try to attend all classes together, so the students will see real team-teaching.

Part of my responsibility at the University of Virginia was covering ethics as part of a twosemester course required of all fourth-year engineering students (see paper by Ingrid Soudek). My colleagues up and down the hall were making increasing use of cases, and I borrowed many of their ideas. But I felt a particular kind of case was missing, one that would connect my earlier work on invention to ethics. Most of the cases we were using were in the late stages of the design. My wife and I had a long-standing interest in solar energy. We found a dynamic young inventor who had created a solar water heating system, and we let him install one on our house. He and I fell to talking, and it occurred to me that his story would make a great case for our students--an ethical inventor-entrepreneur, who wanted to reduce our dependence on fossil fuels, thereby ameliorating the greenhouse effect. to him, it made no sense that we got the heat for our water from a distant power plant, wasting about $70 \%$ of the energy in the process. Why not use the sun and the roof? Surely, millions of people would buy such an obvious solution.

Once again, I turned to the NSF, in this case the ethics and values studies program. The program officer said doing a case on the inventor was a good idea, but I didn't know enough about ethics, and wasn't I aware that an international expert on business ethics was moving to my campus in the fall? This was the start of my collaboration with Pat Werhane, Ruffin Profess of Business Ethics in the Darden School at the University of Virginia. With funding from the NSF, the engineering school and Darden, Pat and I have created a series of cases that explore the links between ethics and design, particularly in the environmental area. ${ }^{1}$

The millions Al Rich hoped for never emerged, although the solar heater on our roof works just fine. From his case, students learn that good intentions are not enough--you have to build a network of collaborators that agree on fundamental principles. For example, one of our cases involves a global network that produced a completely compostable furniture fabric using a clean manufacturing process. Creating and maintaining such networks is part of the act of successful invention. It is also a necessary part of curriculum change.

I have taken cases like the solar heater and the fabric and used them in most of my TCC courses, to show engineering students how design decisions can and must involve an ethical component. The students are not always comfortable with this--they would rather compartmentalize the ethical and design decisions. The former, in their view, and that of many practitioners, should involve issues like corporate conduct; the latter are value-free, 'nuts and bolts' science and

\footnotetext{
${ }^{1}$ Details of this and other cases supported by this grant can be found at http://repo-nt.tcc.virginia.edu, and all are available through the Darden School's case library at
} 
engineering. Doing this kind of work has not made me a more popular teacher, but I think it has made me a better one.

The cases are designed so a wide range of colleagues can use one, including those teaching basic engineering classes. Research on the cases can also be done by engineering students, particularly graduate students. With support from the NSF, the Dean of our Engineering School and the Darden School, I have created a graduate option in Systems Engineering in which Masters \& PhD students do some coursework on ethics, culture and technology and do a thesis focusing on a series of cases. The cases are published with their names on them, as well as presentations at organizations like this one (Gorman, Stocker, \& Mealik, 1997). As a part of this collaboration, I have been given a courtesy appointment in Systems Engineering. Currently, we have our first graduate student from Civil Engineering, and other faculty in our Division are evolving similar relationships with this department.

The model for this graduate option is the same as for the Division's undergraduate mission. Instead of establishing a separate major at both the undergraduate and graduate level, we prefer to collaborate in the development of engineering students who will be ethical professionals with excellent communication skills and an understanding of the role of technology in society.

This is a less glamorous mission than producing replicates of oneself. It means that to teach one's research, one is going to have to establish its relevance to another audience, while still staying on the cutting-edge of one's core area of expertise (see paper by Ed Russell). It means taking an applied perspective on scholarship, much like most engineers. The reward will come if we see our engineering students working to make the world a better place.

\section{Heursitics for Promoting Cross-Disciplinary Collaboration}

1. Team-Teaching: Teaching with a colleague is one of the best ways to learn another perspective and approach. Unfortunately, both of my colleagues in the Invention and Design class were not able to obtain teaching credit for their work on this course--one does it as an overload, and we have had to reduce his commitment. Genuinely collaborative teaching is expensive, although I think it is well worth the expense. One solution is to collaborate across sections of the same or different courses (see paper by Mark Shields).

2. Outside funding, particularly from the NSF, which can stimulate internal recognition and costshare

3. Organizational structures that bring a multi-disciplinary faculty under the same roof with a single mission which they can carry out in a variety of ways, reflecting their own backgrounds, teaching styles, and expertises.

4. Selecting faculty that have a shared sense of commitment to that mission and rewarding them for their hard work. 


\section{References}

Carlson, W. B., \& Gorman, M. E. (1990). Understanding invention as a cognitive process: The case of Thomas Edison and early motion pictures, 1888-1891. Social Studies of Science, 20, 387430.

Feist, G., \& Gorman, M. E. (In Press). The psychology of science: Review and integration of a nascent discipline. Review of General Psychology.

Gorman, M. E., \& Carlson, W. B. (1990). Interpreting invention as a cognitive process: The case of Alexander Graham Bell, Thomas Edison and the telephone. Science, Technology and Human Values, 15, 131-164.

Gorman, M. E., Mehalik, M. M., Carlson, W. B., \& Oblon, M. (1993). Alexander Graham Bell, Elisha Gray and the Speaking Telegraph: A Cognitive Comparison. History of Technology, 15, $1-56$.

Gorman, M. E., Richards, L. G., Scherer, W. T., \& Kagiwada, J. K. (1995). Teaching invention and design: Multi-disciplinary learning modules. The Journal of Engineering Education, 84(2), 175-186.

Gorman, M. E., Stocker, J., \& Mehalik, M. M. (1997, ). Using detailed, multimedia cases to teach engineering ethics. Paper presented at the American Society for Engineering Education, Milwaukee, WI.

Okada, T., \& Simon, H. A. (1997). Collaborative discovery in a scientific domain. Cognitive Science, 21(2), 109-146. 